\title{
PROFA. DRA. JUDITH FELCMAN - SUA VIDA ACADÊMICA E CONTRIBUIÇÃO À CIÊNCIA
}

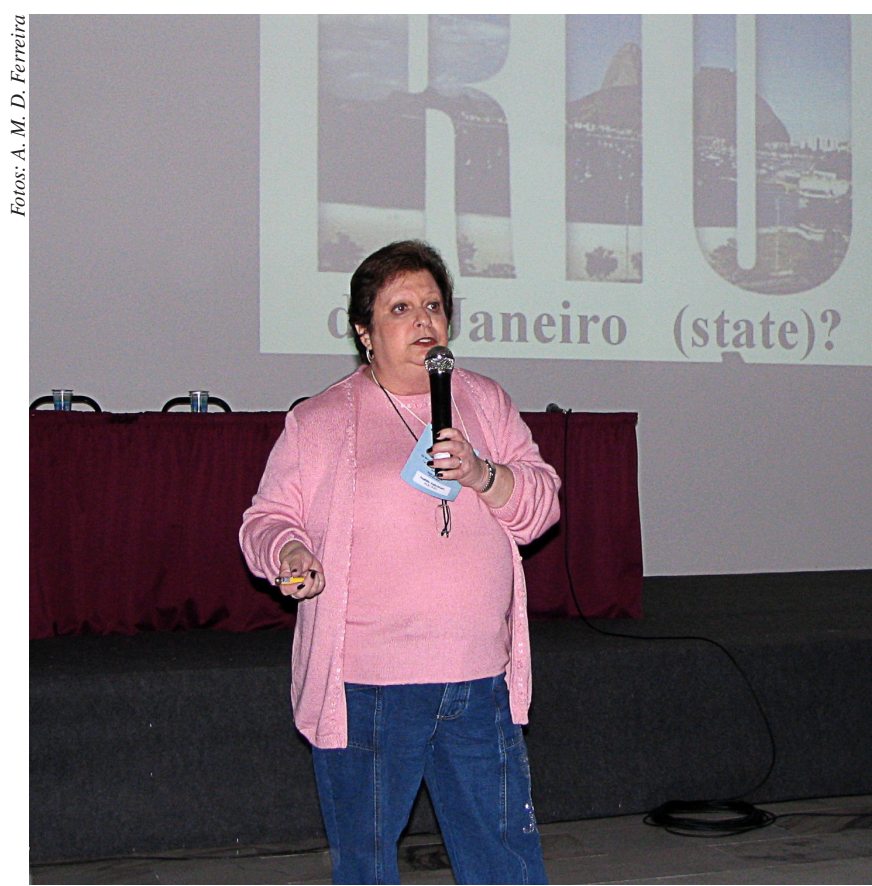

$3 / 5 / 1941-16 / 3 / 2012$

Judith Felcman nasceu em 3 de maio de 1941, na cidade do Rio de Janeiro. Graduou-se em Farmácia pela Universidade Federal do Rio de Janeiro em 1962, e completou o mestrado em Química, em 1980, sob orientação do Prof. Hans Joacchim Eichhoff, na Pontifícia Universidade Católica (PUC-RJ). Judith passou a ter uma atuação destacada na Química Inorgânica e Analítica brasileira após 1983, quando obteve seu doutorado com João J. R. Frausto da Silva, renomado Professor da Universidade Técnica de Lisboa, com quem prosseguiu no pós-doutorado em 1985 e 1989. Sua tese focalizou o papel do vanádio na biologia, e nela explorou com propriedade a natureza dos complexos de oxo-vanádio(IV) com ácidos poliaminocarboxílicos e sua ocorrência no cogumelo Amanita muscaria. Mais do que um trabalho de tese, foi o início de uma importante linha de pesquisa em uma área que, na época, era ainda incipiente em todo o mundo. Tratava-se da Química Bioinorgânica. Hoje, é uma das áreas mais férteis dentro da Química, principalmente por conjugar os princípios e diversidade dos elementos inorgânicos com os processos da vida, transpondo a Tabela Periódica dos Elementos para o universo dos sistemas biológicos.

Sua trajetória acadêmica na PUC-RJ, desde 1978 até o presente, é repleta de contribuições importantes para o ensino, pesquisa e extensão. Coordenou inúmeras atividades e comissões estatutárias, incluindo a de Pós-Graduação e foi Diretora do Departamento de Química da PUC-RJ. Conduziu um grande número de projetos, tanto acadêmicos como aplicados à área de Petróleo, com captação de recursos e produção de resultados relevantes para a PETROBRAS. Orientou 48 teses de mestrado e doutorado, publicou 54 artigos em periódicos indexados, 3 livros, 4 capítulos de livro e apresentou mais de uma centena de comunicações em congressos nacionais e internacionais. Foi coeditora de vários livros, incluindo o Molecular and Supramolecular Bioinorganic Chemistry - Applications in Medical Sciences, publicado em 2009 pela Nova Science Publishers Inc., N. York (EUA).

No âmbito nacional e internacional, Judith Felcman tornou-se bastante conhecida e respeitada por sua intensa participação em atividades científicas, organizando ou frequentando congressos e eventos, como o ICBIC (International Conference on Biological Inorganic Chemistry, Viena, 2007). Na área de Química Inorgânica, a realização do IV Simpósio Nacional de Química Inorgânica na PUC-RJ, em 1988, sob sua coordenação, foi um marco importante para o desenvolvimento da área no Brasil.

Foi delegada do Brasil e membro da Comissão de Dados e Constantes de Equilíbrio da IUPAC (International Union of Pure and Aplied Chemistry) de 1996 a 1999. Prestou serviços importantes para as agências e órgãos de fomento, bem como para as revistas científicas, participando ativamente em bancas examinadoras de teses e concursos públicos. Sua atuação e respeitabilidade contribuíram para elevar o conceito do Departamento de Química da PUC-RJ no cenário nacional e internacional. Foi membro da Diretoria da Divisão de Química Inorgânica da Sociedade Brasileira de Química no período de 2002 a 2008. Sua presença constante no meio científico, sempre acompanhada de um carinhoso sorriso, era sua característica marcante. Judith, professora, cientista e amiga, sua vida ficará para sempre na lembrança da comunidade científica brasileira.

Henrique E. Toma

IQ - USP

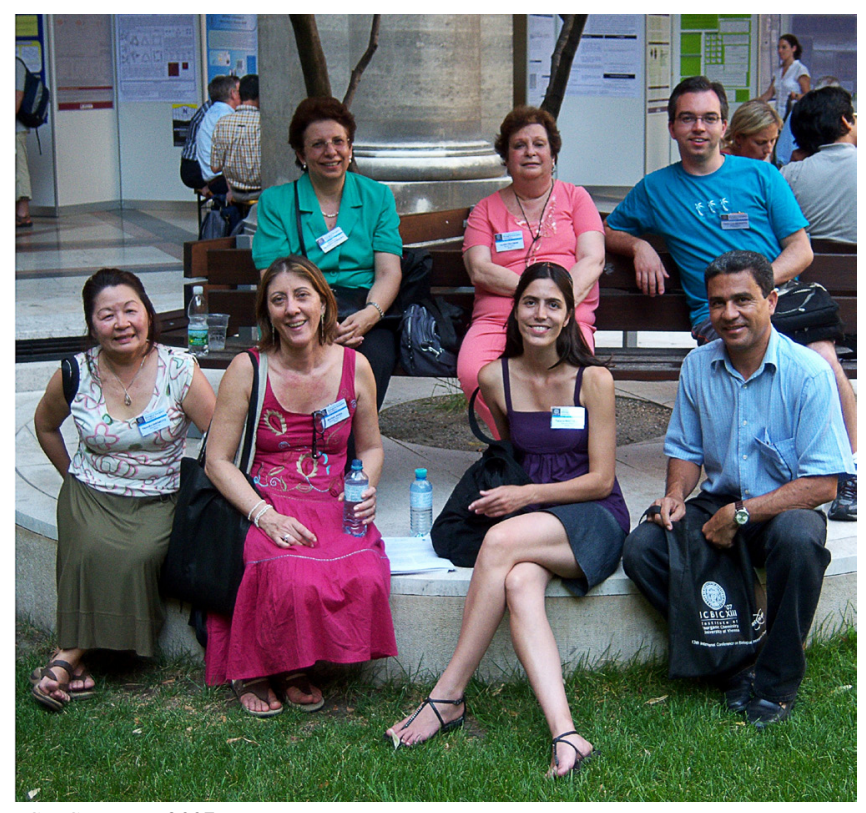

ICBIC - Viena, 2007 